\title{
Environmental factors influence on flowering and fruiting period of selected essential oil plants from Annonaceae
}

\author{
DEWI AYU LESTARI", ABBAN PUTRI FIQA ${ }^{* \bullet}$ \\ Purwodadi Botanic Gardens, Research Center for Plant Conservation and Botanic Gardens, Indonesia Institute of Sciences (LIPI). Jl. Surabaya-Malang \\ Km. 65, Purwodadi, Pasuruan 67163, East Java, Indonesia. Tel./fax.: +62-343-615033, •email: chunyang_dee@yahoo.co.id, •vabbanpf@gmail.com
}

Manuscript received: 26 December 2019. Revision accepted: 6 February 2020.

\begin{abstract}
Lestari DA, Fiqa AP. 2020. Environmental factors influence on flowering and fruiting period of selected essential oil plants from Annonaceae. Biodiversitas 21: 910-921. Many species of Annonaceae family in tropics produce fragrances, due to the active ingredients for essential oils. Since the abundant of flower and fruit production, basic knowledge of flowering and fruiting periods needs to be known. The aim of this study was to determine influence of environmental factors to selected essential oil plants flowering and fruiting period from Annonaceae family, i.e. Artabotrys suaveolens, Cananga odorata, Desmos chinensis, Dasymaschalon borneense, Fissistigma latifolium, and Xylopia malayana. Observations were made throughout the year during dry and rainy season, with each phase carried out scoring qualitatively based on its abundance in plant canopy. Data on environmental factors (temperature, humidity, and rainfall intensity) were obtained from Registration Unit, Purwodadi Botanic Garden (PBG). Data of flowering and fruiting period were analyzed descriptively using Microsoft Excel, while the influence of environmental factors to flowering and fruiting period was analyzed by Biplot with Past 3.0. statistic program. Flowering period occurred in wet months at the end of year (November-December), while fruiting period occurred in long dry month. Initiation and bloom of flowering were influenced by temperature, while fruiting period was largely influenced by humidity and rainfall intensity, except for $C$. odorata whose fruiting period was influenced by temperature.
\end{abstract}

Keywords: Annonaceae, environmental factors, essential oils, flowering, fruiting

\section{INTRODUCTION}

Plants are living things that rich in active ingredients sources, which are used by chemical and pharmaceutical industries as raw material for certain products. One of products produced is essential oil. Essential oils are one example of vegetable oil from organic compounds that contain many benefits and are obtained through distillation process of plant parts such as roots, rhizomes, stems, leaves, flowers, fruits and seeds. Essential oils have a distinctive aroma and volatile cause its to be used as basis for making fragrances in cosmetics industry (Mangun 2006; Rusli 2010). The plants that produce essential oils have a large and varied amount, one of which is plant species from Annonaceae family.

Many species of Annonaceae family in tropics produce fragrances, because they contain active ingredients for essential oils. In Annonaceae, the active ingredient component for each different plant species is predominantly obtained from flowers, fruit, leaves, bark and seed coat (Fournier et al. 2011). Plant parts of Annonaceae family that known as essential oil source production are flower and fruit, those were obtained through extraction process on it in a large number. Essential oils from Artabotrys spp. fragrances (Phan et al. 2011; Thang et al. 2013), fresh flower extraction of Cananga odorata (Putri et al. 2019), fresh leaf extraction from Desmos spp. (Dai et al. 2012), root, bark and fruit extraction of Monanthotaxis diclina and Unonopsis guatterioides (Fournier et al. 1997), leaf extraction from Pseuduvaria spp. (Brophy et al. 2004), leaf extraction from Xylopia aethiopica (Karioti et al. 2004) and various essential oils produced from various species of Annonaceae family.

Basic understanding of flowering and fruiting period needs to be known, since the blooming periods of flowering and fruiting become important as it was the raw materials for essential oil production. By understanding how and when plant flowering and fruiting period then we might understand the physiological processes of plants and the response of plants to their environment (Brennan 1996; Khanduri et al. 2013; Micheloud et al. 2018). This environmental factor is important since it is related to the response of flowering and fruiting plants. Environmental factors can influence quality and quantities of essential oils were produced. This is because it influences the active ingredients production or secondary metabolites used as components of essential oils (Duarte et al. 2018).

Plant flowering and fruiting patterns in tropics are very sensitive to environmental factors fluctuations such as temperature and rainfall intensity. If the environmental conditions do not allow plants flowering and fruiting, the plants will delay the flowering and fruiting period or also it might reducing its intensity until environmental conditions were allowed (Anderson et al. 2005). Environmental factors will influence pattern and productivity of flowers and fruits through shifting flowering and fruiting seasons (Winarni et al. 2016), especially specific micro- 
environment to plant growth (Wahyuni et al. 2012; Panchen 2016). The aim of this study was to determine the most influence of environmental factors to flowering and fruiting period in selected essential oil plants from Annonaceae family, which give some benefit economically to the people so people might interest to conserve this local plant.

\section{MATERIALS AND METHODS}

\section{Study area}

Research was conducted from 2011 to 2014 at Purwodadi Botanic Garden (PBG), Indonesia Institute of Sciences (LIPI), Pasuruan, East Java (Figure 1). Selected essential oil plants from Annonaceae family that observed include Artabotrys suaveolens, Cananga odorata, Desmos chinensis, Dasymaschalon borneense, Fissistigma latifolium, and Xylopia malayana. These species were known to have floral scents such as fruit or cananga oil.

\section{Procedures}

Observation was made once a week throughout the year, to determine flowering and fruiting patterns during rainy and dry seasons. The parameters observed were the percentage of leaves (immature and senescence), flowers (bud and bloom), and fruit (immature and ripe). Each phase was scaled qualitatively based on its abundance in the plant canopy (Hatta and Darnaedi 2005; Nanda et al. 2014). Secondary data of environmental factors i.e. temperature, humidity, and rainfall intensity during 2011-2014 were obtained from Registration Unit of PBG.

\section{Data analysis}

Data were analyzed descriptively using Microsoft Excel to determine flowering and fruiting period. The influence of environmental factors for flowering and fruiting periods was analyzed by Biplot method using statistical program PAST ver. 3.

\section{RESULTS AND DISCUSSION}

\section{Flowering and fruiting period of selected essential oil plants from Annonaceae}

The flowering period of selected essential oil plants from Annonaceae family occurs in wet month at the end of the year (November-December), while the fruiting period occurs in the long dry month (April-October). Species of $D$. chinensis, $C$. odorata, and $D$. borneense have subannual flowering patterns (occurs more than one cycle in a year) and species of $A$. suaveolens, $F$. latifolium, and $X$. malayana have annual flowering patterns (only occur one cycle in one year) (Table 1). The fruiting pattern is generally supra-annual (one cycle length needs more than one year). D. borneense did not produce fruit during observations; nevertheless, this species produces flowers every year.

\section{The influence of environmental factors on flowering and fruiting periods}

The appearance of immature leaves was generally influenced by temperature factors, except for X. malayana which was influenced by humidity and rainfall intensity. Whereas, the appearance of senescence leaves was generally negatively influenced by humidity and rainfall intensity, except for $D$. borneense whose appearance of immature and senescence leaves were influenced by temperature. Plants of $C$. odorata was influenced by temperature, and species of $F$. latifolium was positively influenced by humidity and rainfall intensity, while $X$. malayana was negatively influenced. Positive effect means that if the environmental factors are large, the production of leaves, flowers, and fruit is also large, and vice versa. Negative effect means that if the environmental factors are big, so that leaves, flowers and fruit productions are small, and vice versa. Each flowering and fruiting behavior in one species can be influenced by different environmental factors, as well as the same flowering and fruiting behavior in different species can also be influenced by different environmental factors.
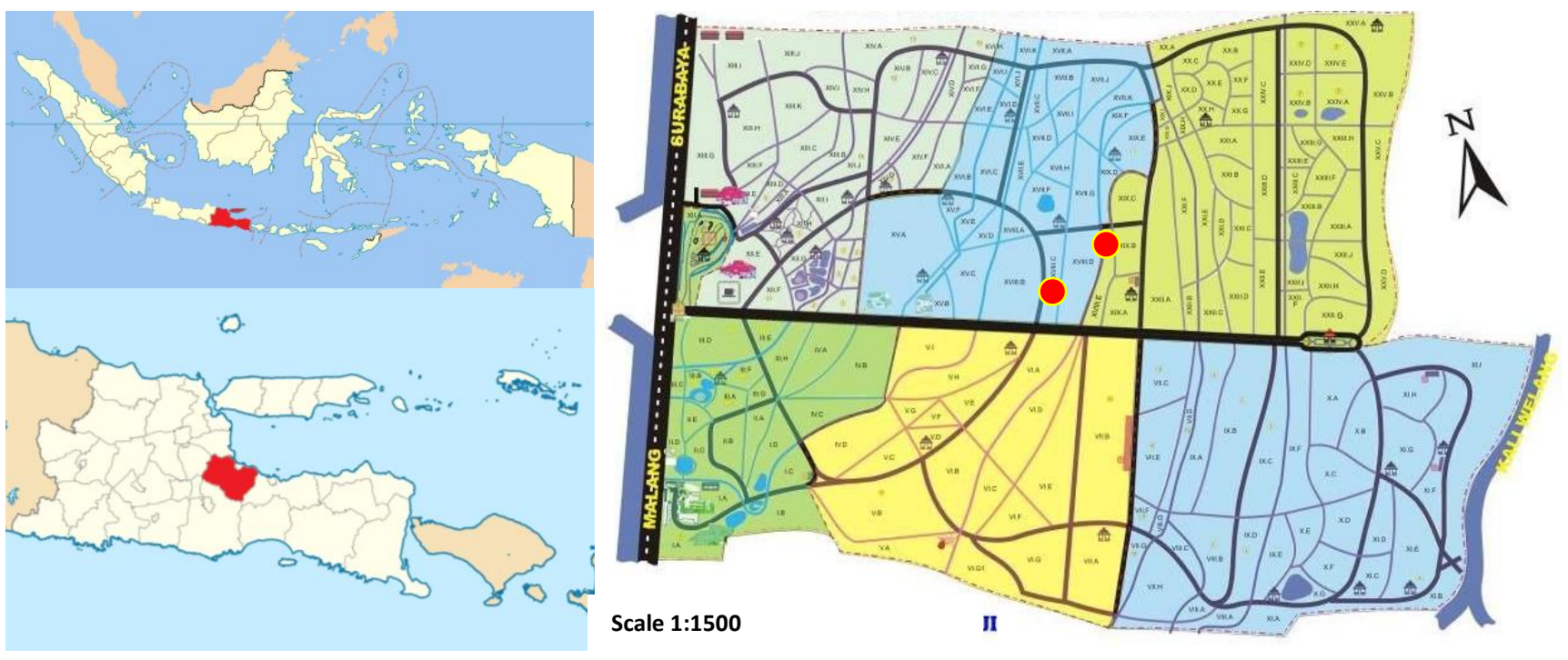

Figure 1. Research location in PBG, Pasuruan, East Java, Indonesia (red circle symbol is observation location) 
Table 1. Flowering and fruiting period of selected essential oil plants from Annonaceae

\begin{tabular}{|c|c|c|c|c|c|c|c|c|c|c|c|c|c|}
\hline \multirow{2}{*}{ Species } & \multirow{2}{*}{ Year } & \multicolumn{12}{|c|}{ Flowering and fruiting period } \\
\hline & & Jan & Feb & Mar & Apr & May & Jun & Jul & Aug & Sep & Oct & Nov & Dec \\
\hline \multirow{4}{*}{ A. suaveolens } & 2011 & & & & & & & & & & & & \\
\hline & 2012 & & & & & & & & & & & & \\
\hline & 2013 & & & & & & & & & & & & \\
\hline & 2014 & & & & & & & & & & & & \\
\hline \multirow[t]{4}{*}{ C. odorata } & 2011 & & & & & & & & & & & & \\
\hline & 2012 & & & & & & & & & & & & \\
\hline & 2013 & & & & & & & & & & & & \\
\hline & 2014 & & & & & & & & & & & & \\
\hline \multirow[t]{4}{*}{ D. chinensis } & 2011 & & & & & & & & & & & & \\
\hline & 2012 & & & & & & & & & & & & \\
\hline & 2013 & & & & & & & & & & & & \\
\hline & 2014 & & & & & & & & & & & & \\
\hline \multirow[t]{4}{*}{ D. borneense } & 2011 & & & & & & & & & & & & \\
\hline & 2012 & & & & & & & & & & & & \\
\hline & 2013 & & & & & & & & & & & & \\
\hline & 2014 & & & & & & & & & & & & \\
\hline \multirow{4}{*}{ F. latifolium } & 2011 & & & & & & & & & & & & \\
\hline & 2012 & & & & & & & & & & & & \\
\hline & 2013 & & & & & & & & & & & & \\
\hline & 2014 & & & & & & & & & & & & \\
\hline \multirow[t]{4}{*}{$X$. malayana } & 2011 & & & & & & & & & & & & \\
\hline & 2012 & & & & & & & & & & & & \\
\hline & 2013 & & & & & & & & & & & & \\
\hline & 2014 & & & & & & & & & & & & \\
\hline
\end{tabular}

Note: $\quad$ : flowering, : _ fruiting, _ flowering and fruiting

Generally, flowering and fruiting behavior in $A$. suaveolens was most influenced by humidity (Table 2). Flowering initiation process of $A$. suaveolens was influenced by temperature, while fruiting initiation process was positively influenced by rainfall intensity. Besides them, fruiting initiation process was also negatively influenced by temperature (PC 2) in Table 2. Another phenological behavior, such as the appearance of immature leaves, was also influenced by temperature (Figure 2).

The flowering period of $A$. suaveolens was influenced by the ambient temperature. Generally, an enhancement of temperature initiates flower buds formation and followed by flowering formation (Figure 3). Flowering phase of this species was finished when temperature drops. Different from flowering period, the initial fruiting period was influenced by rainfall intensity. However, rainfall intensity can initiate fruiting only occurs in 2011-2012, beginning with a month without long rains and then followed by high rainfall intensity (up to $24 \mathrm{~mm}$ in a month). Fruiting initiation period was finished when the rainfall intensity was low.

In contrast to $A$. suaveolens, the most influential environmental factor in $C$. odorata flowering and fruiting behavior is rainfall intensity, as seen on PC 2 (Table 3). However, the environmental factor was influencing flowering initiation was temperature, although not very significant. Fruiting initiation and formation of this species were also influenced by temperature. In addition, temperature also influences to immature leaves initiation (Figure 4).
On average, $C$. odorata periods of flowering only stop for 4 months per year. Based on statistics, the flowering period was influenced by temperature, but flowering pattern and its relationship to temperature fluctuations were less clear (Figure 5). Fruiting period of this species was also influenced by temperature fluctuations. In year of 2011 and 2012, fruiting period clearly occurred when the highest temperature, but the fruiting period was changed in year of 2013 and 2014. The fruit only occurs in the middle of the year (2013), while in 2014, this species actually fruiting on four times (at the beginning of the year, midyear and end of the year).

Temperature was the most influenced an environmental factor in the flowering and fruiting period of $D$. chinensis (Table 4 on PC 2). Same with the other species, flowering period of $D$. chinensis was also influenced by temperature. Initiation of fruiting in this species was positively influenced by humidity and rainfall intensity, but negatively influenced by temperature. Senescence leaves was negatively influenced by rainfall intensity and humidity (Table 4, Figure 6).

The flowering initiation process of $D$. chinensis was begun with the rising temperature which was higher than normal (Figure 7). Flowering period of this species would end if the temperature decreases back to usual $\left( \pm 25^{\circ} \mathrm{C}\right)$. Fruiting period of this species has annual frequency and was usually influenced by increasing rainfall intensity and humidity in their environment. 
Rainfall intensity was the most influential factor in $D$. borneense flowering and fruiting period (the greatest value in Table 5 on PC 1). The bud and bloom flower initiation process in this species was influenced by temperature. Temperature also influences to the immature and senescence leaves initiation process (Figure 8). The environmental factors were influenced by fruiting period cannot be determined, because of this species never fruiting during observations.

D. borneense has a quite high flowering frequency compared to the other species were observed. Qualitatively, this species would be initiate of bud flower when temperatures tend to be high (Figure 9), followed by flower bloom. Although has continual frequency to flowering, this species does not produce any fruit during the observation done.

Generally, humidity was giving influence to the $F$. latifolium flowering and fruiting period (Table 6 on PC2). Initiation of bud flower until bloom flower and immature leaves process in this species was influenced by temperature. Meanwhile, the initiation of immature fruit until ripe fruit process was influenced by humidity and rainfall intensity, and also negatively influenced by temperature (Table 6, Figure 10).

Table 2. Eigenvalue of environmental factors influence to flowering and fruiting period of $A$. suaveolens

\begin{tabular}{lll}
\hline & PC 1 & PC 2 \\
\hline Flowering and fruiting activity & & \\
Lim & $\mathbf{0 . 2 0 6 7 1}$ & -0.1348 \\
Lse & $\mathbf{- 0 . 2 0 7 1 9}$ & -0.087609 \\
FlBud & $\mathbf{0 . 5 0 6 3 9}$ & -0.3142 \\
FlB1 & $\mathbf{0 . 5 2 8 7 9}$ & -0.31244 \\
FrIm & 0.28335 & $\mathbf{0 . 3 1 0 3 7}$ \\
FrRipe & $\mathbf{- 0 . 2 3 2 7 8}$ & -0.091046 \\
Environmental factor & & \\
RF & 0.40639 & $\mathbf{0 . 4 4 5 4 7}$ \\
RH & 0.17296 & $\mathbf{0 . 6 2 4 7}$ \\
T & 0.22079 & $\mathbf{- 0 . 2 9 0 6 8}$ \\
\hline
\end{tabular}

Table 3. Eigenvalue of environmental factors to flowering and fruiting period of $C$. odorata

\begin{tabular}{lll}
\hline & PC 1 & PC 2 \\
\hline Flowering and fruiting activity & & \\
Lim & $\mathbf{0 . 4 2 2 8 8}$ & 0.2632 \\
Lse & 0.051542 & $\mathbf{- 0 . 4 2 5 3 6}$ \\
FlBud & $\mathbf{0 . 4 6 4 0 7}$ & -0.068145 \\
FlB1 & $\mathbf{0 . 5 1 4 6 9}$ & -0.036051 \\
FrIm & 0.18314 & $\mathbf{0 . 3 8 8 0 9}$ \\
FrRipe & 0.15474 & $\mathbf{0 . 4 0 1 7}$ \\
Environmental factor & & \\
RF & -0.23493 & $\mathbf{0 . 4 3 8}$ \\
RH & -0.38377 & $\mathbf{0 . 3 9 3 7 4}$ \\
T & 0.2798 & $\mathbf{0 . 2 9 1 5 4}$ \\
\hline
\end{tabular}

Table 4. Eigenvalue of environmental factors to flowering and fruiting period of $D$. chinensis

\begin{tabular}{lll}
\hline & PC 1 & PC 2 \\
\hline Flowering and fruiting activity & & \\
Lim & $\mathbf{0 . 2 9 2 3 7}$ & 0.061232 \\
Lse & $\mathbf{- 0 . 3 4 2 3 3}$ & 0.13851 \\
FlBud & $\mathbf{0 . 3 9 4 8 3}$ & 0.36827 \\
FlBl & $\mathbf{0 . 3 9 1 7 4}$ & 0.27867 \\
FrIm & 0.15748 & $\mathbf{- 0 . 5 1 9 3 3}$ \\
FrRipe & $\mathbf{- 0 . 3 3 3 1 3}$ & -0.15336 \\
Environmental factor & & \\
RF & $\mathbf{0 . 4 2 9 7 9}$ & -0.21645 \\
RH & $\mathbf{0 . 3 9 5 5 2}$ & -0.39393 \\
T & 0.10513 & $\mathbf{0 . 5 1 8 2}$ \\
\hline
\end{tabular}

Table 5. Eigenvalue of environmental factors to flowering and fruiting period of $D$. borneense

\begin{tabular}{lll}
\hline & PC 1 & PC 2 \\
\hline Flowering and fruiting activity & & \\
Lim & 0.077117 & $\mathbf{0 . 4 6 2 0 3}$ \\
Lse & -0.28731 & $\mathbf{0 . 4 4 6 5 2}$ \\
FlBud & 0.40205 & $\mathbf{0 . 4 6 9 4 8}$ \\
FlB1 & 0.43035 & $\mathbf{0 . 4 4 6 8 4}$ \\
Environmental factor & & \\
RF & $\mathbf{0 . 5 6 1 2 2}$ & -0.23707 \\
RH & $\mathbf{0 . 4 9 8 9 8}$ & -0.30403 \\
T & -0.026836 & $\mathbf{0 . 1 3 5 7 4}$ \\
\hline
\end{tabular}

Table 6. Eigenvalue of environmental factors to flowering and fruiting period of $F$. latifolium

\begin{tabular}{lll}
\hline & PC 1 & PC 2 \\
\hline Flowering and fruiting activity & & \\
Lim & $\mathbf{0 . 4 5 7 6 3}$ & -0.17897 \\
Lse & $\mathbf{- 0 . 3 0 9 7 7}$ & -0.091605 \\
FlBud & $\mathbf{0 . 4 9 8 7 8}$ & -0.14262 \\
FlBl & $\mathbf{0 . 5 2 6 5 3}$ & -0.060692 \\
FrIm & 0.054009 & $\mathbf{0 . 1 3 8 7 9}$ \\
FrRipe & 0.036276 & $\mathbf{0 . 3 0 7 6 8}$ \\
Environmental factor & & \\
RF & 0.28127 & $\mathbf{0 . 5 3 3 7}$ \\
RH & 0.10689 & $\mathbf{0 . 6 6 5 4 7}$ \\
T & 0.27173 & $\mathbf{- 0 . 3 0 6 4 9}$ \\
\hline
\end{tabular}

Table 7. Eigenvalue of environmental factors to flowering and fruiting period of $X$. malayana

\begin{tabular}{lll}
\hline & PC 1 & PC 2 \\
\hline Flowering and fruiting activity & & \\
Lim & $\mathbf{0 . 4 5 7 6 3}$ & -0.17897 \\
Lse & $\mathbf{- 0 . 3 0 9 7 7}$ & -0.091605 \\
FlBud & $\mathbf{0 . 4 9 8 7 8}$ & -0.14262 \\
FlBl & $\mathbf{0 . 5 2 6 5 3}$ & -0.060692 \\
FrIm & 0.054009 & $\mathbf{0 . 1 3 8 7 9}$ \\
FrRipe & 0.036276 & $\mathbf{0 . 3 0 7 6 8}$ \\
Environmental factor & & \\
RF & 0.28127 & $\mathbf{0 . 5 3 3 7}$ \\
RH & 0.10689 & $\mathbf{0 . 6 6 5 4 7}$ \\
T & 0.27173 & $\mathbf{- 0 . 3 0 6 4 9}$ \\
\hline
\end{tabular}




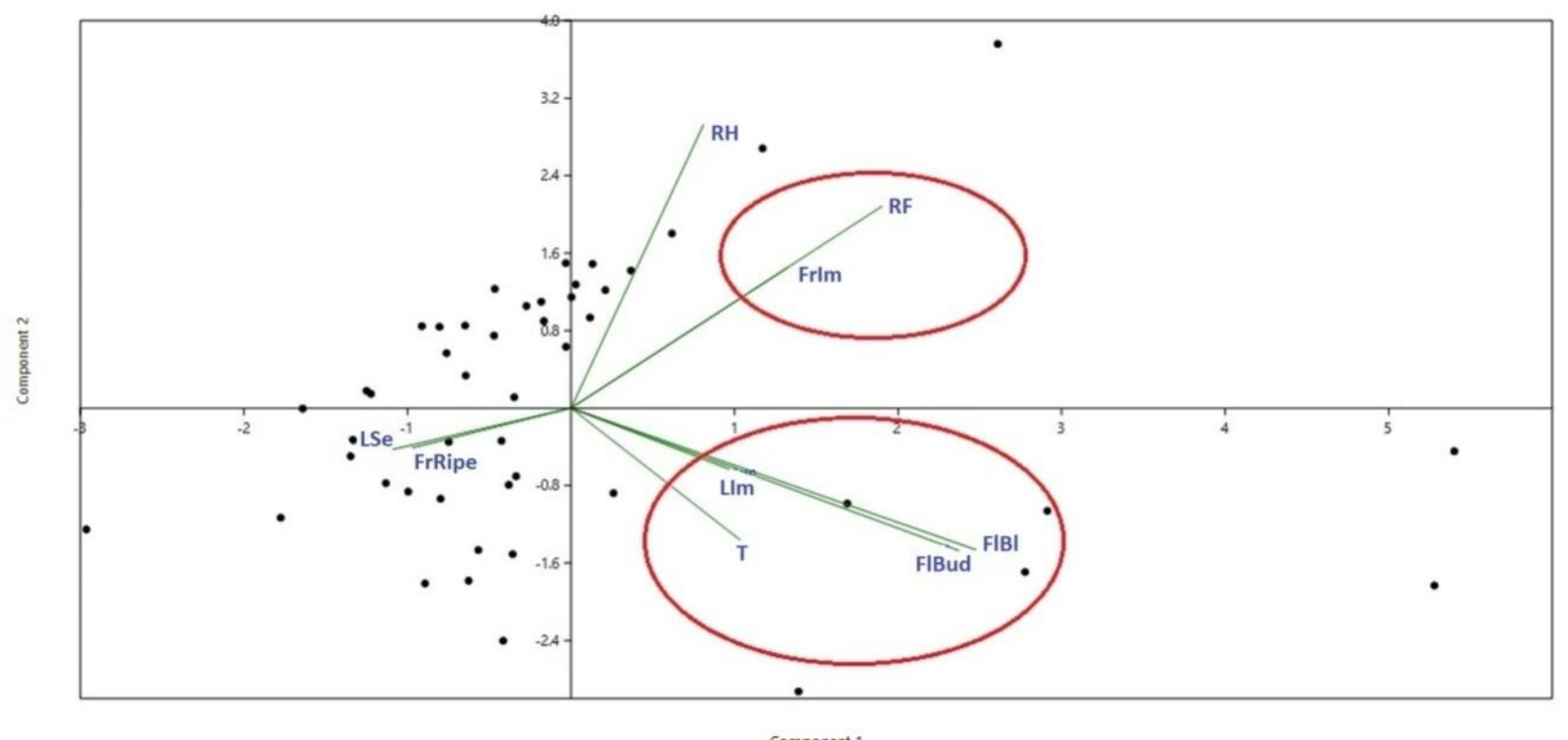

Figure 2. Diagram of environmental factor influence to flowering and fruiting period of A. suaveolens; RH: humidity, RF: rainfall intensity, T: temperature, Lim: immature leaves, Lse: senescence leaves, FlBud: flower bud, FlBl: flower bloom, Frim: immature fruit, FrRipe: ripe fruit. Value of component 1 explains $27.77 \%$ of all environmental factors were observed, while component 2 explains $20.30 \%$.
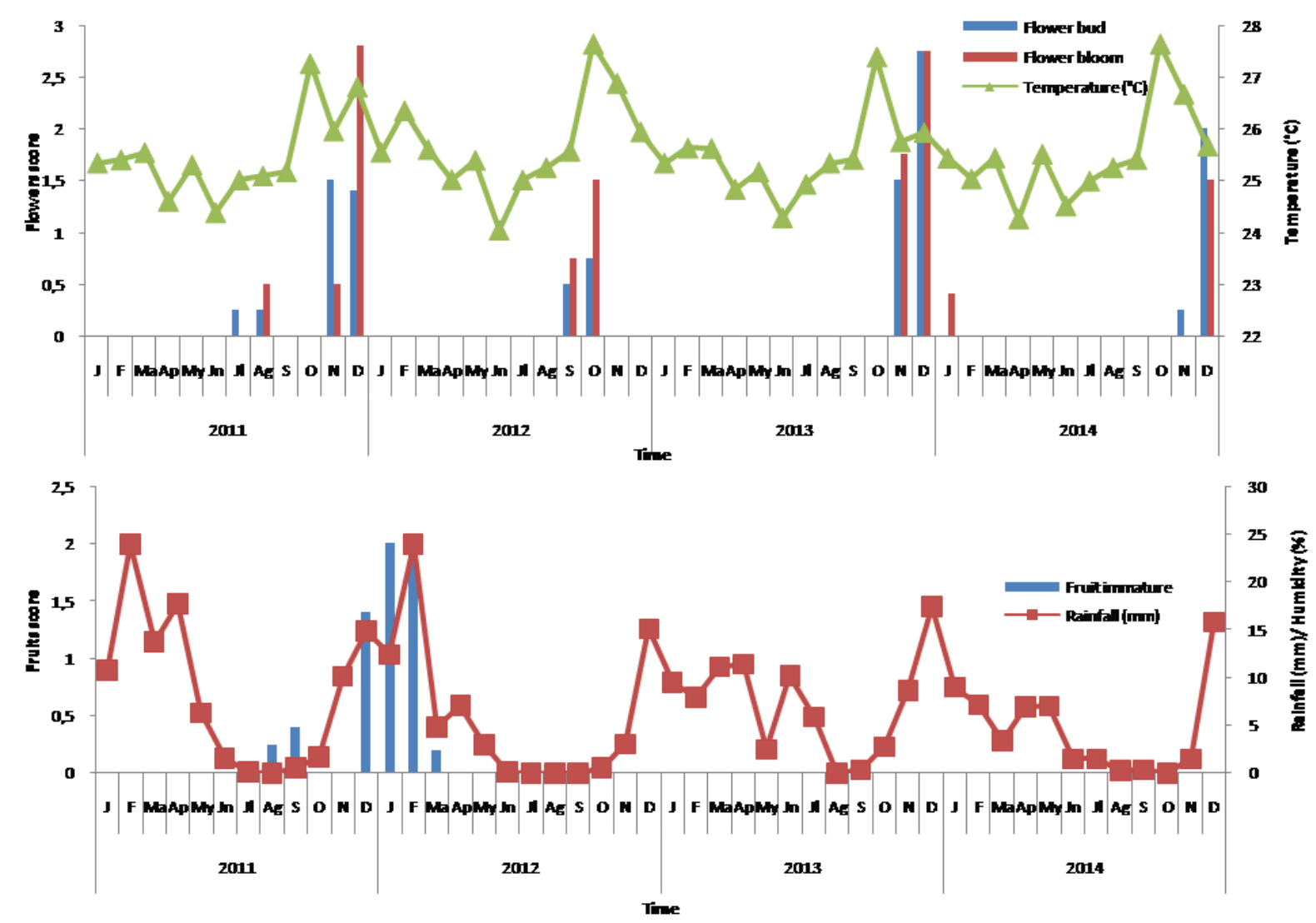

Figure 3. Relationship of environmental factor with flowering and fruiting period of A. suaveolens 


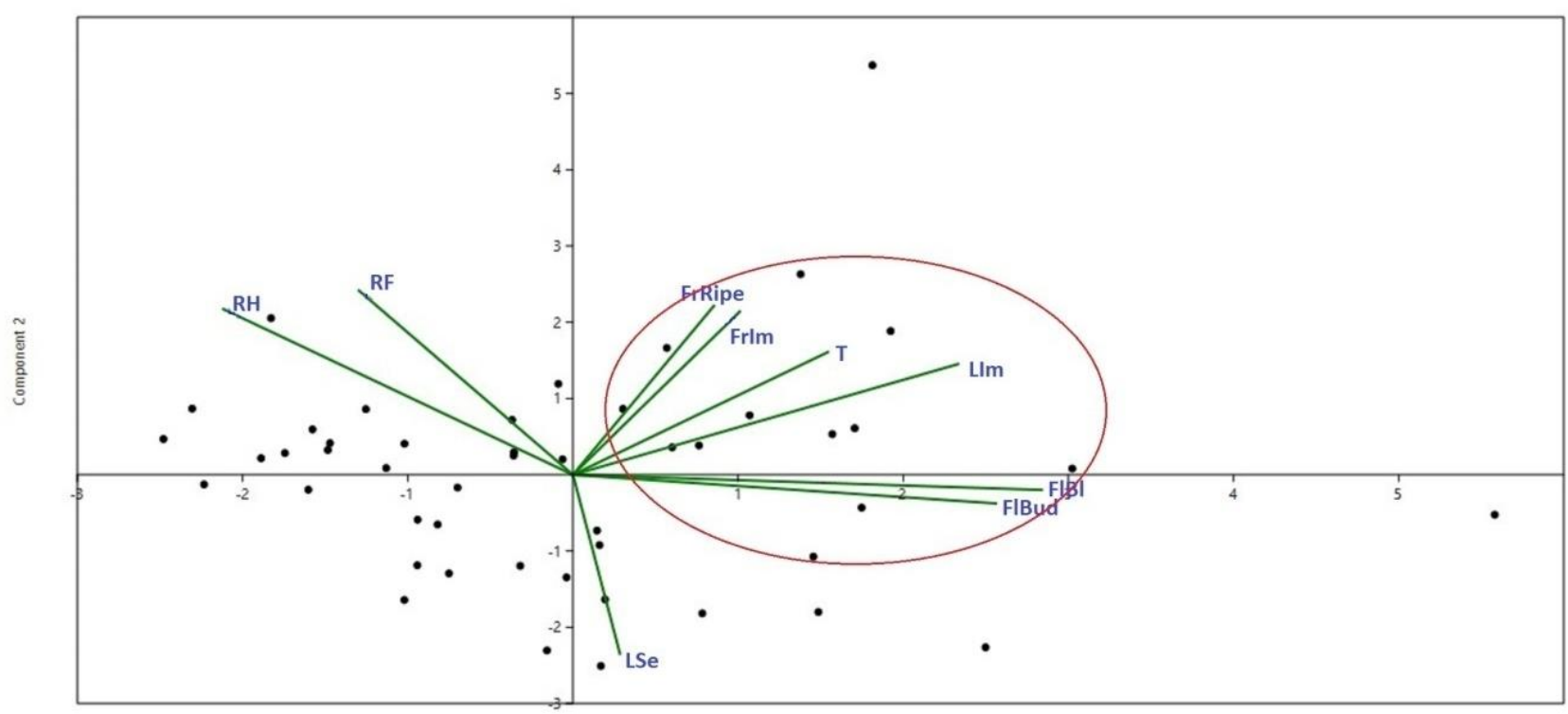

Component 1

Figure 4. Diagram of environmental factor influence to flowering and fruiting period of C. odorata; RH: humidity, RF: rainfall intensity, T: temperature, Lim: immature leaves, Lse: senescence leaves, FlBud: flower bud, FlBl: flower bloom, Frim: immature fruit, FrRipe: ripe fruit. Value of component 1 explains $27.47 \%$ of all environmental factors was observed, while component 2 explains $21.79 \%$.

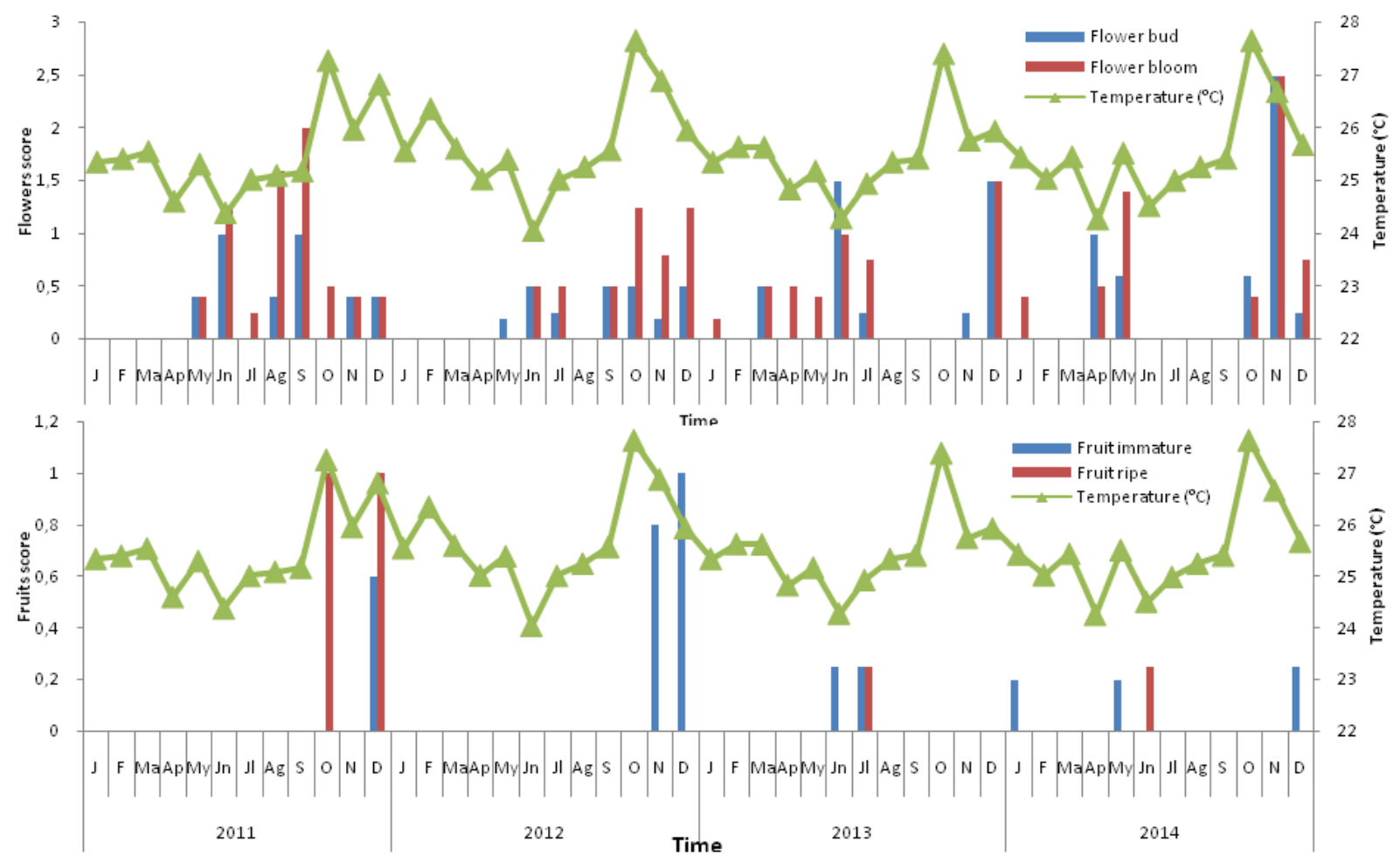

Figure 5. Relationship of environmental factor with flowering and fruiting period of C. odorata 


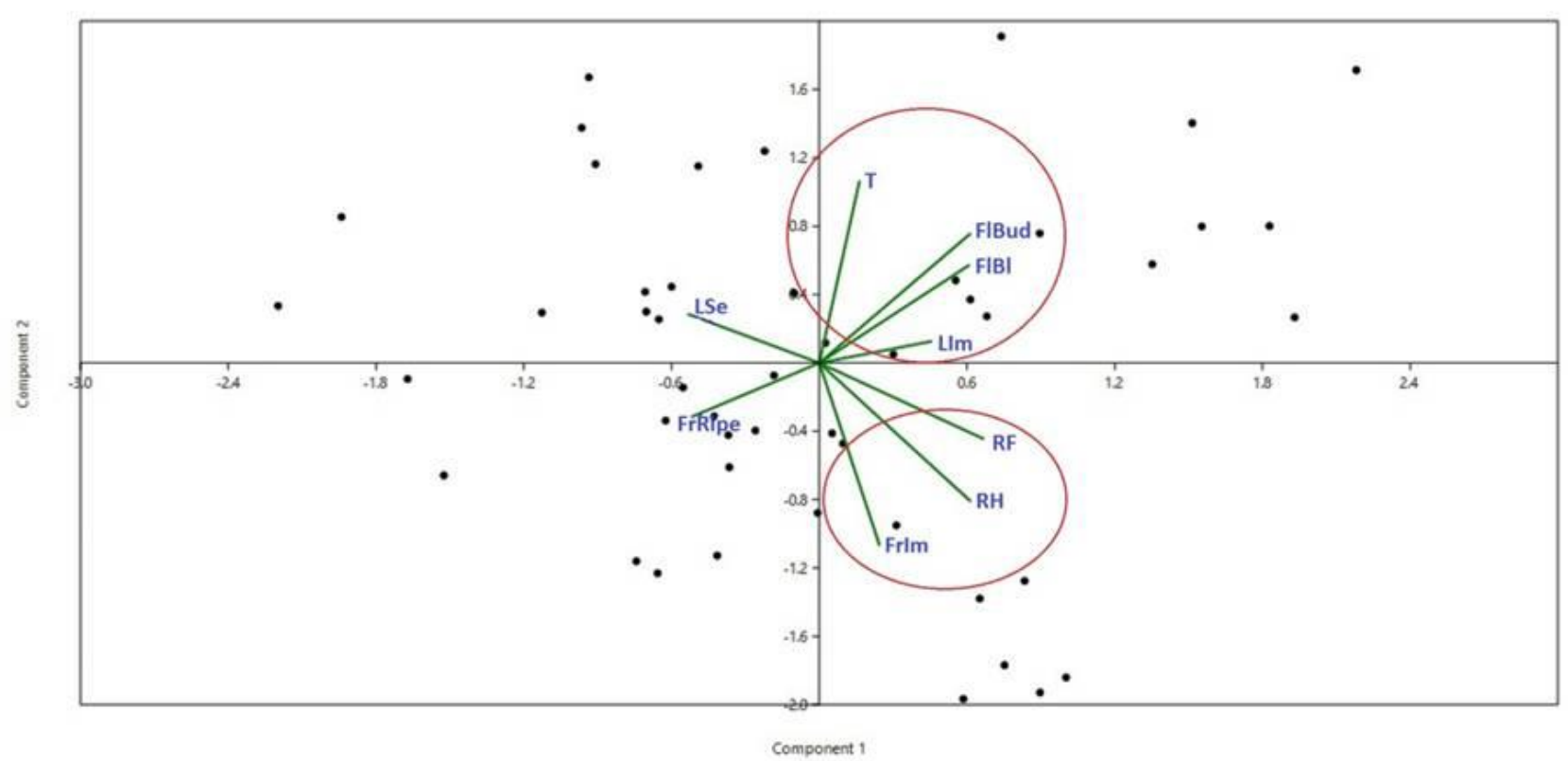

Figure 6. Diagram of environmental factor influence to flowering and fruiting period of $D$. chinensis; RH: humidity, RF: rainfall intensity, T: temperature, Lim: immature leaves, Lse: senescence leaves, FlBud: flower bud, FlBl: flower bloom, Frim: immature fruit, FrRipe: ripe fruit. Value of component 1 explains $34.23 \%$ of all environmental factors were observed, while component 2 explains $19.56 \%$.
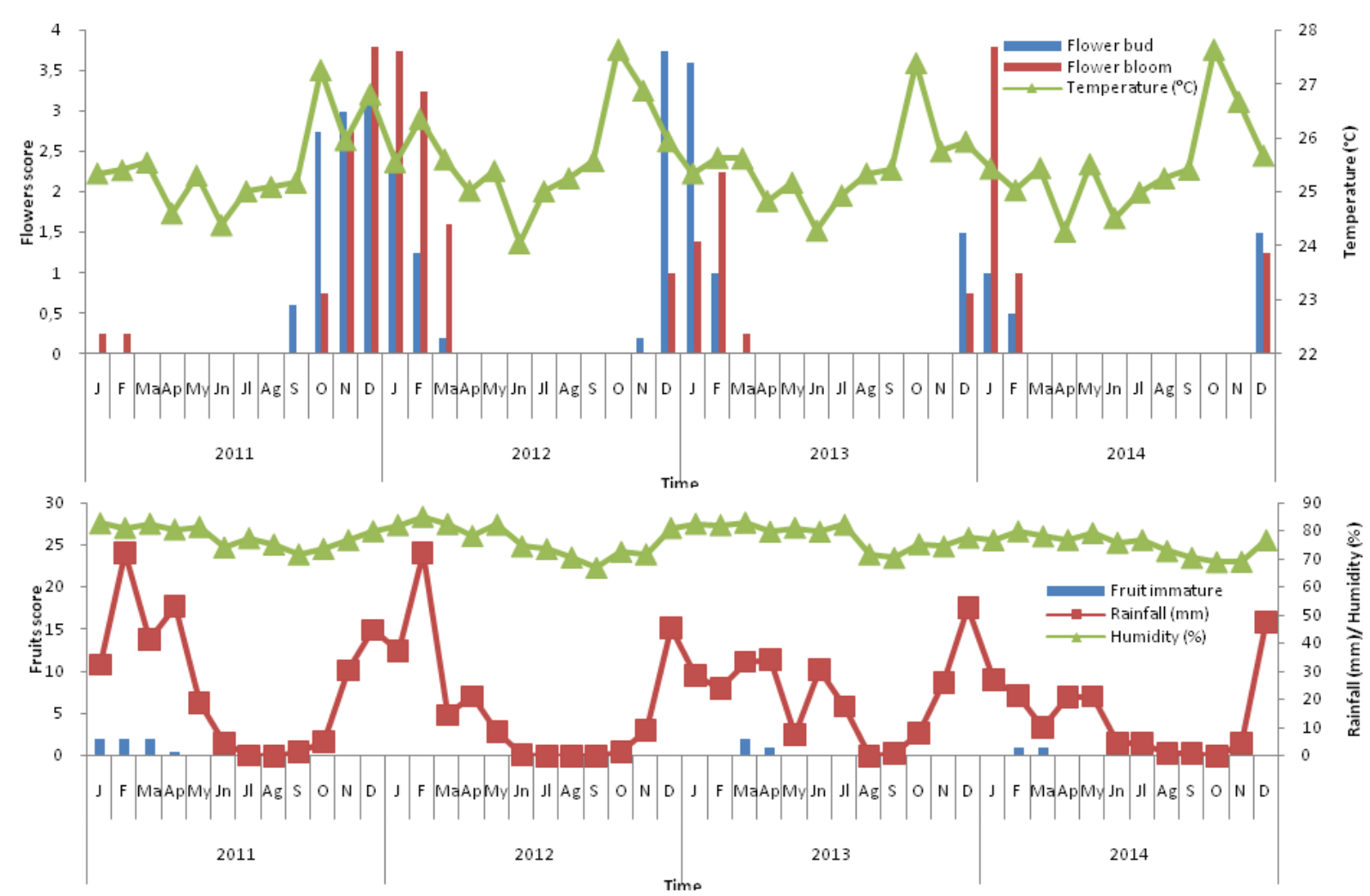

Figure 7. Relationship of environmental factor with flowering and fruiting period of D. chinensis 


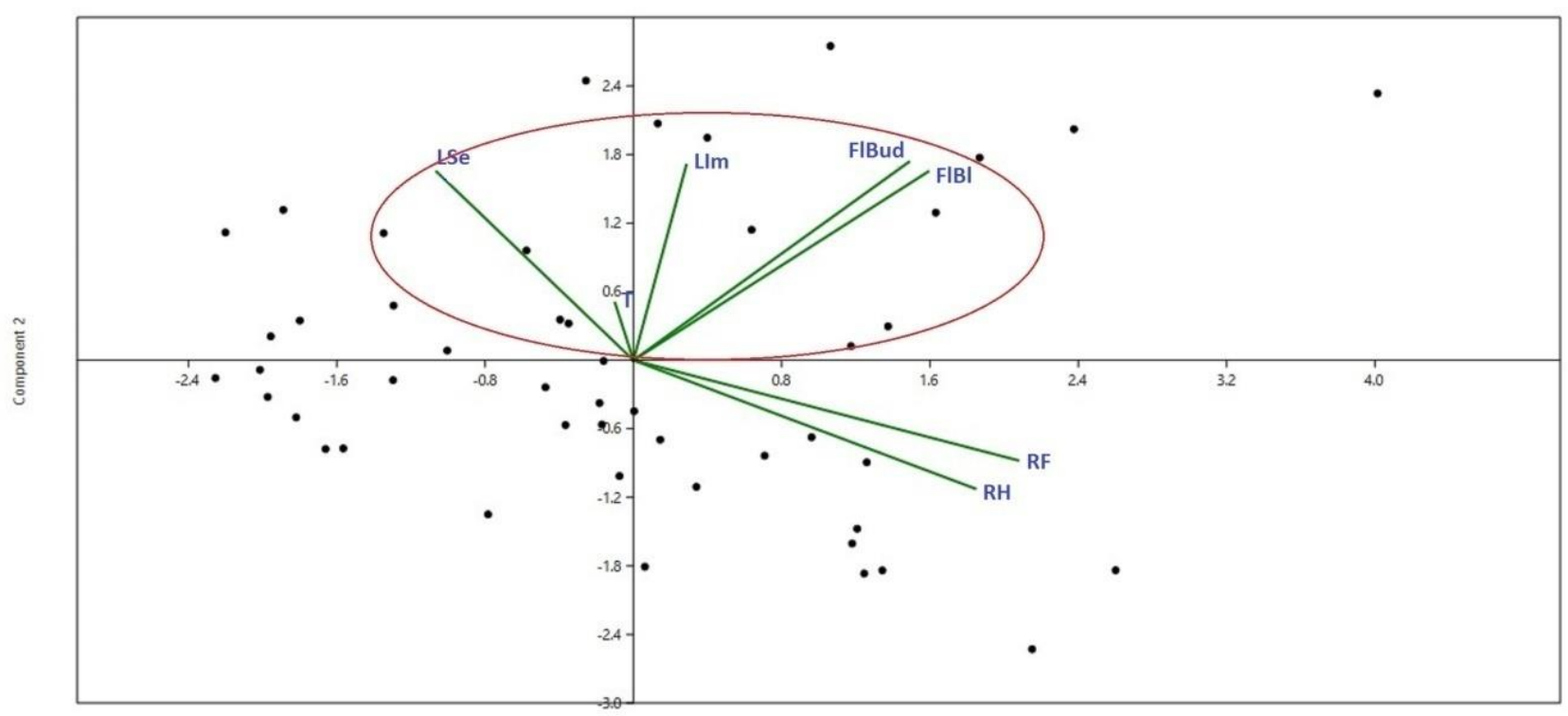

Component 1

Figure 8. Diagram of environmental factor influence to flowering and fruiting period of $D$. borneense; RH: humidity, RF: rainfall intensity, T: temperature, Lim: immature leaves, Lse: senescence leaves, FlBud: flower bud, FlBl: flower bloom, Frim: immature fruit, FrRipe: ripe fruit. Value of component 1 explains $29.97 \%$ of all environmental factors were observed, while component 2 explains $23.39 \%$.

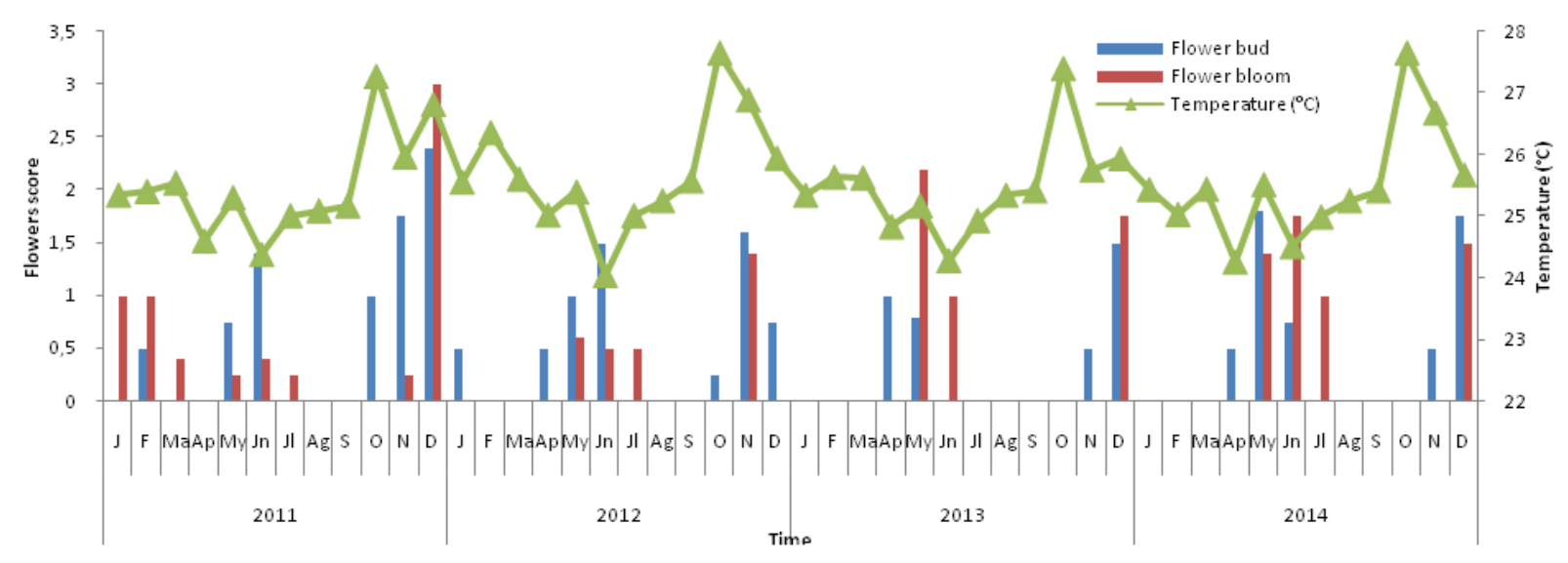

Figure 9. Relationship of environmental factor with flowering and fruiting period of $D$. borneense

Qualitatively, the flowering period pattern of $F$. latifolium based on statistical tests was influenced by temperature (Figure 11). The flowering period of this species was influenced by an enhancement of temperature above from monthly average, and the flowering period would end when temperature decreases. Meanwhile, based on the statistical test, fruiting period of this species was influenced by humidity and rainfall intensity. Humidity that tends to be high and stable will trigger of fruiting, while high rainfall intensity will trigger of fruiting initiation period. $F$. latifolium starts to ripe fruit when the third year of observation takes place (2013) and this pattern would repeat which was preceded by an enhancement of rainfall intensity.
Rainfall intensity was the most influenced environmental factor to the X. malayana flowering and fruiting period (Table 7 on PC1). In this species, temperature was influenced by the flowering initiation of this species, but bloom flower was actually influenced by rainfall intensity and humidity. Temperatures give negatively effect to the fruit immature formation process, while ripe fruit process was negatively influenced by humidity and rainfall intensity. The process of immature leaves formation was negatively influenced by temperature, while senescence leaves was negatively influenced by rainfall intensity and humidity (Figure 12). 


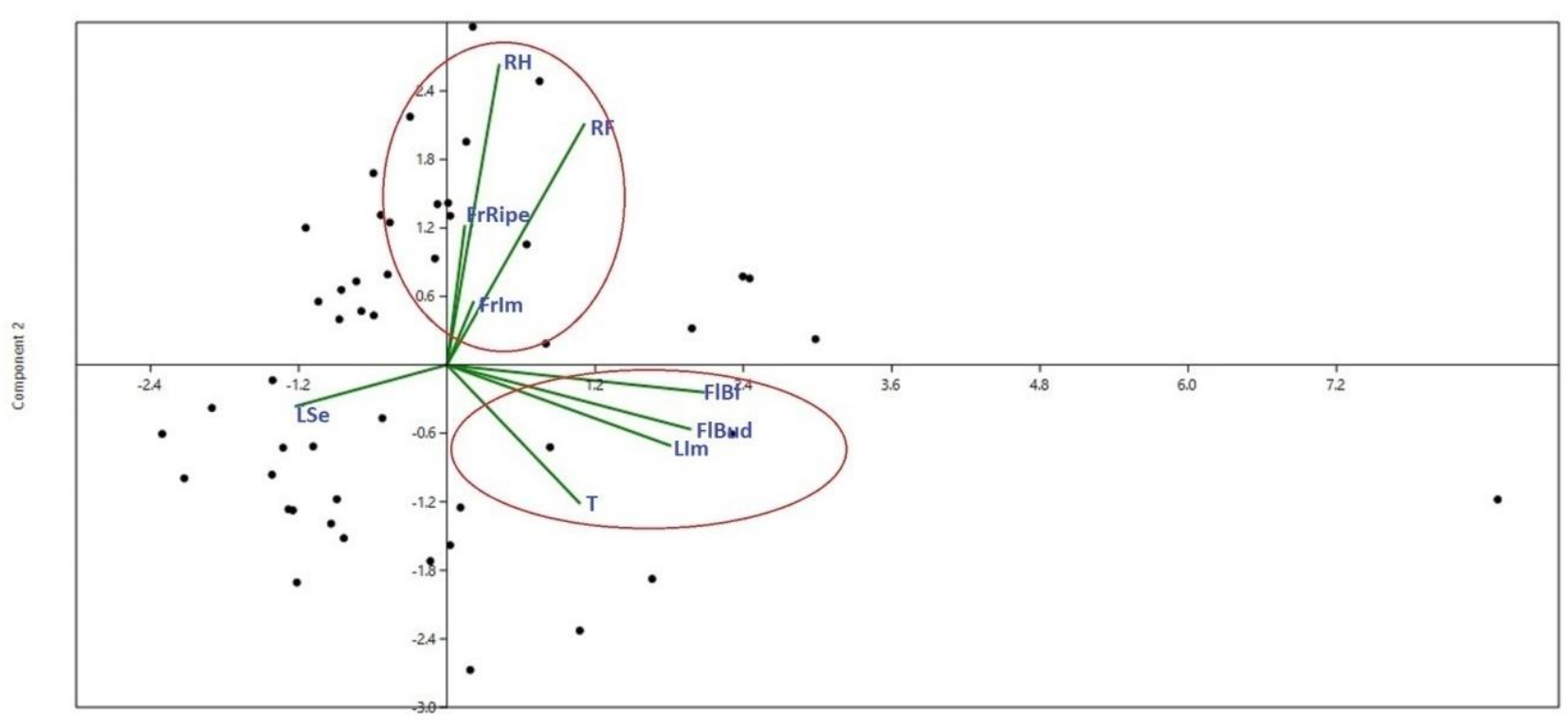

Component 1

Figure 10. Diagram of environmental factor influence to flowering and fruiting period of $F$. latifolium; RH: humidity, RF: rainfall intensity, T: temperature, Lim: immature leaves, Lse: senescence leaves, FlBud: flower bud, FlBl: flower bloom, Frim: immature fruit, FrRipe: ripe fruit. Value of component 1 explains $33.74 \%$ of all environmental factors were observed, while component 2 explains $19.88 \%$.

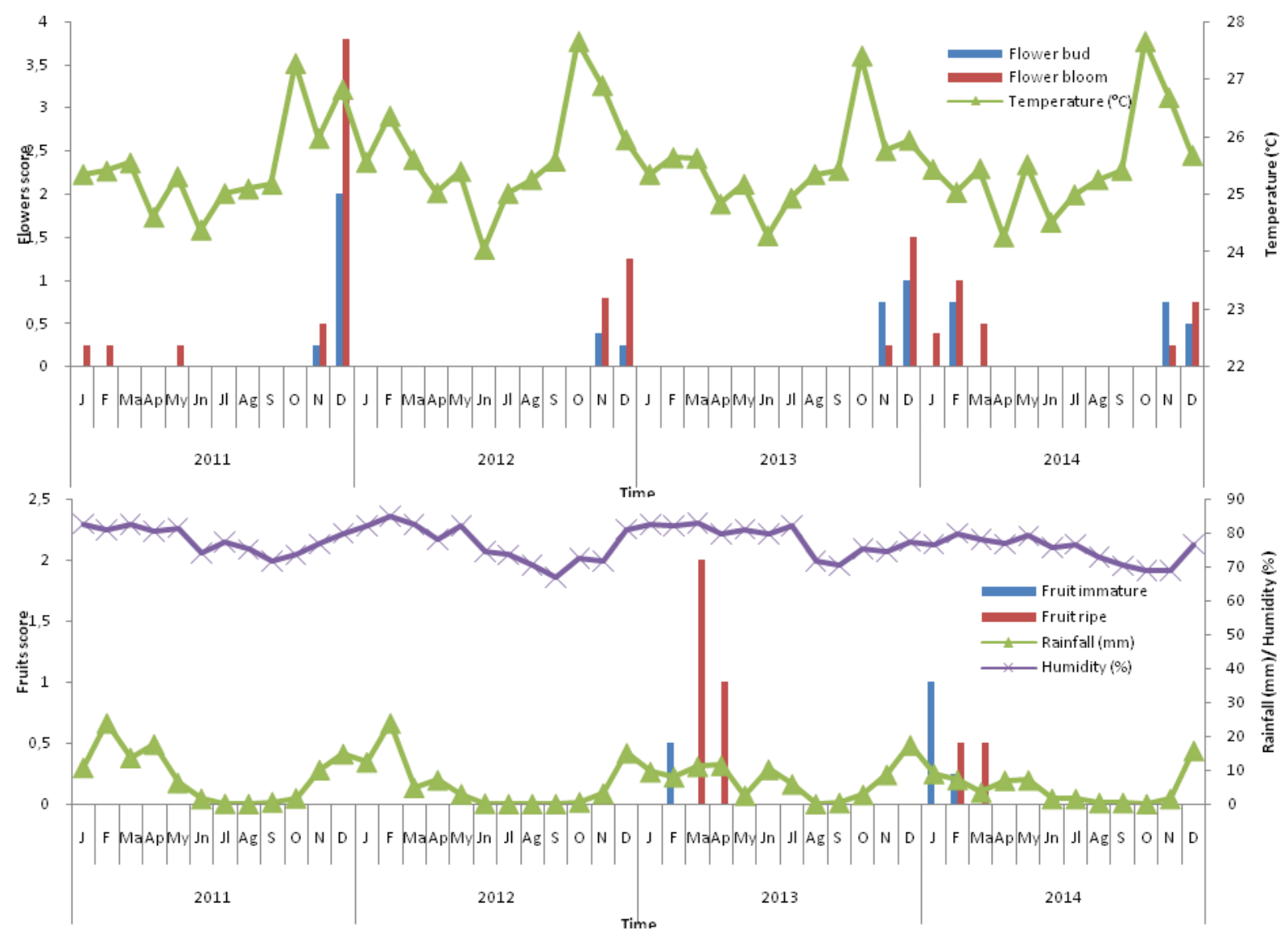

Figure 11. Relationship of environmental factor with flowering and fruiting period of $F$. latifolium 
Based on statistical tests, flowering period of $X$. malayana was influenced by many factors. Flowering initiation was influenced by temperature, but unfortunately, it did not show qualitatively in Figure 13. Flower buds begin to initiate and the intensity will be increased after temperature drops, from high initially. The development of flowers to bloom was influenced by rainfall intensity and humidity. Flowers bloom would initiate by an enhancement of rainfall intensity and humidity (more humid point). Meanwhile, the pattern of X. malayana fruiting period statistically has not been proven to be influenced by environmental factors, because of $X$. malayana has only ripe fruit once during the observation (in 2012). Qualitatively, this species has begun to ripe fruit during a dry month and was stable for four months at its lowest point.

\section{Discussion}

Lestari (2019) states that the peak of flowering in Annonaceae plant collection in PBG occurs during the wet month and the peak of fruiting occurs consistently during the dry month with a fairly long period of time between November and February. The reproductive phase will decrease along with the increase of temperature during the dry season (Danarto 2013). D. borneense is quite productive in producing flowers, but it will be quite difficult to develop, because this species has difficulty producing fruit. The species that are easily developed and introduced to the surrounding community as oil-producing plants are A. suaveolens, C. odorata, and D. chinensis. These species are native plant in Indonesia (powo.science.kew.org. 2019), the basic of flowering and fruiting period from these species can be used to conserve if planted by community.

The appearance of flower buds and bloom flowers were greatly influenced by temperature factors. This is inversely proportional to the statement from Handayani (2016) which states that the most influential environmental factor on flowering Annonaceae is rainfall intensity, but does not influence the conception of Annonaceae. The emergence of fruit both immature and ripe fruit was more influenced by humidity and rainfall intensity.

Considering that the essential oils productions were used flowers as the material, the micro-temperature that affect flower production around species selected needs more attention. This aims to produce abundant flowers. Generally, the temperature required by selected essential oil plant species from Annonaceae in the range of $24.05^{\circ} \mathrm{C}$ $27.65^{\circ} \mathrm{C}$. Selected essential oils plants species from Annonaceae will produce abundant flowers when the temperature is moderate. The lowest phase for Annonaceae plant collections in PBG during flowering is in the dry season (Lestari 2019). According to Anderson et al. (2005), the percentage of flowering plants during the dry season in the dry tropical forests is very low and flower production will be abundant when sufficient water is available or occurs in the wet month.

The appearance of immature leaves was generally influenced by temperature, while the appearance of senescence leaves was negatively influenced by rainfall intensity and humidity. Janzen (1974) and Nanda et al. (2017) states that rainfall intensity gives a significant negative effect on the appearance of senescence leaves. This indicates that senescence leaves initiation began to occur during the dry season period. If there is a generative phase during the dry season, it will provide benefits for these plant species because the energy from its resources was shared for vegetative and generative phase's growth. Therefore, each plant species during the flowering and fruiting phases will be influenced by specific environmental factors, while the biophysical character of each plant was also different (Wahyuni et al. 2012). Generally, environmental factors will give influences the plants production (Bawa et al. 2003). The essential oils obtained through a part of plant in a certain amount.

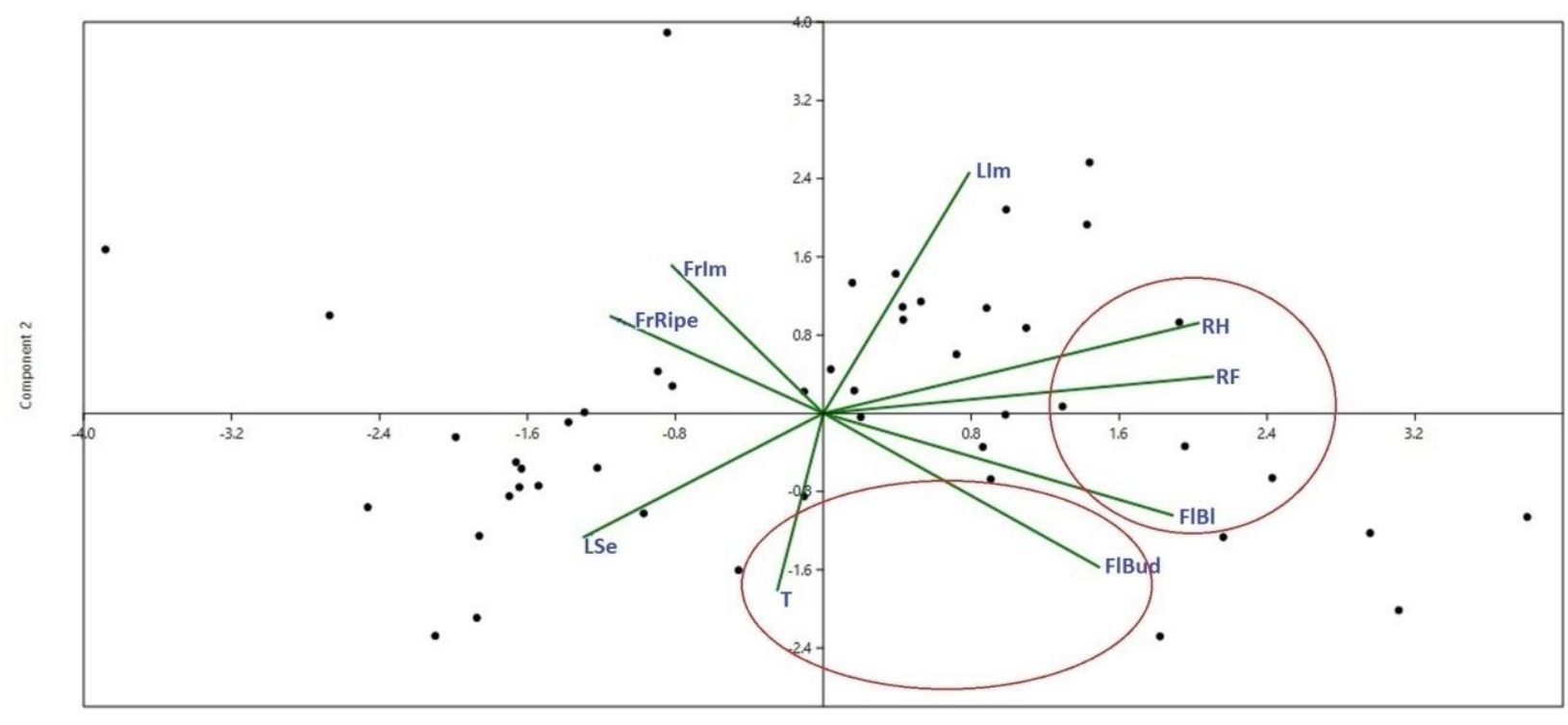

Figure 12. Diagram of environmental factor influence to flowering and fruiting period of $X$. malayana; RH: humidity, RF: rainfall intensity, T: temperature, Lim: immature leaves, Lse: senescence leaves, FlBud: flower bud, FlBl: flower bloom, Frim: immature fruit, FrRipe: ripe fruit. Value of component 1 explains $31.31 \%$ of all environmental factors were observed, while component 2 explains $18.52 \%$ 


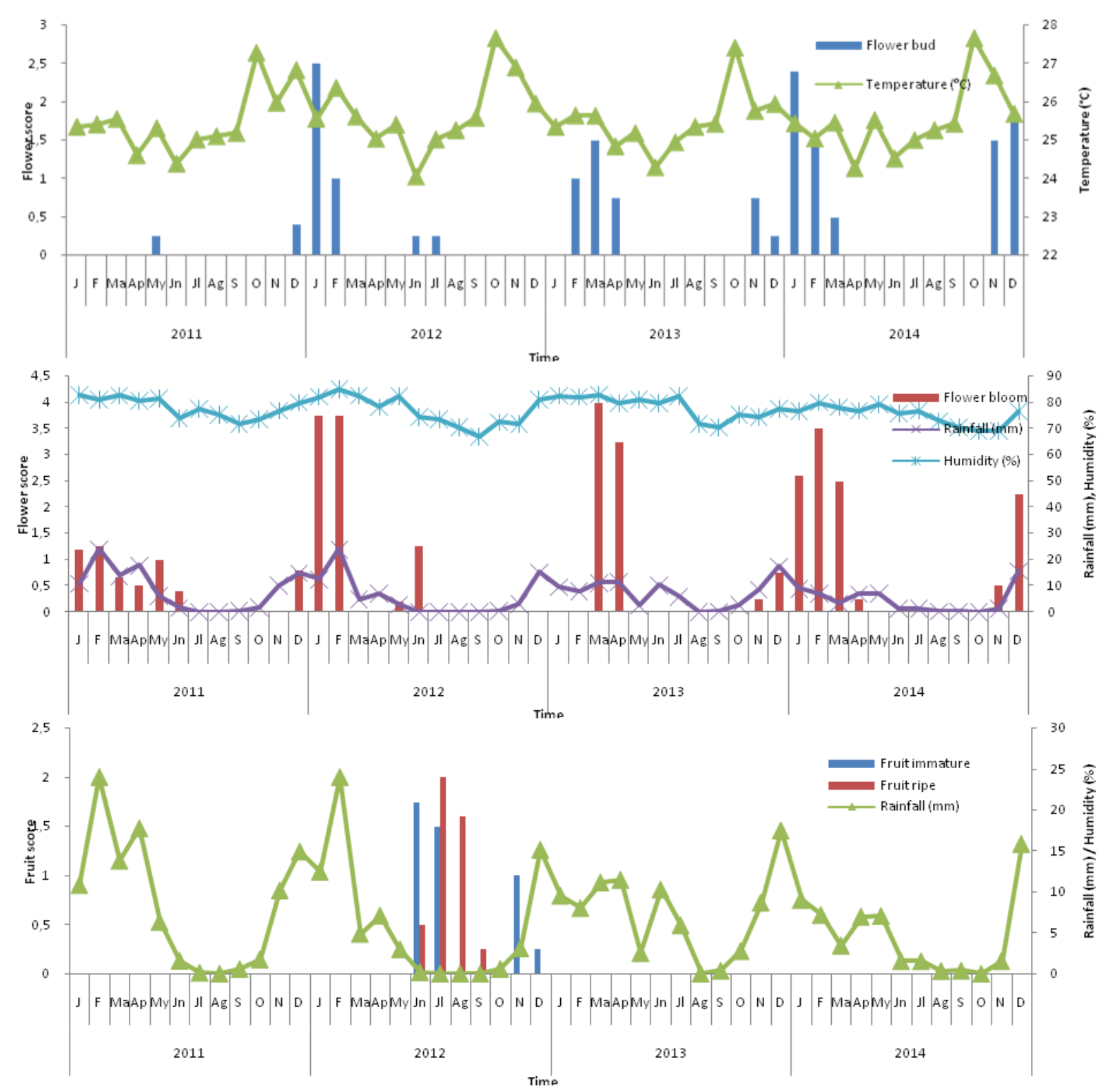

Figure 13. Relationship of environmental factor with flowering and fruiting period of X. malayana

Even though on essential oils production flower numbers on selected species become main attention, but the whole phenology process still important to consider. It is known from the research result that leaves abundance does not indicate the flower abundance; however other species of Annonaceae such as Desmos, Xylopia, and Pseuduvaria produce essential oils from their leaves (Brophy et al. 2004; Karioti et al. 2004; Dai et al. 2012). In addition, fruiting process becomes important to pay attention since it affects on seed production that will use on plant propagation.

The period of flowering and fruiting in plants is a natural period that is seasonal and commonly known as phenology. Phenology is closely related to environmental factors. Because events in phenology are seasonal, they are often influenced by temperature factors. Plants species in sub-tropical regions have earlier flowering and fruiting periods than in the tropics. Microclimate is the most important factor and has a significant influence on flowering and fruiting periods compared to height and location (Panchen 2016). The peak of flowering will occur at the end of the dry month and the peak of fruiting will occur at the beginning of the wet month (Kurten et al. 2018).

Natural phenomena occurring in plant life cycles such as leaf senescence, flowering, and fruiting, generally vary depending on environmental conditions, especially for plant species that can live in a wide range of climatic and edaphic types (Cleland et al. 2012). Each species of plant will have different flowering and fruiting behavior patterns, but in general, it starts with flower bud initiation and ends with fruit maturity (Tabla and Vargas 2004; Syamsuwida et al. 2014). Phenological studies on the six species of Annonaceae plant collections in PBG have the potential to produce essential oils. This is showed that temperature has 
a positive influence on the flowering initiation process for all species observed. Meanwhile, the bloom flower process is influenced by different factors in each species.

\section{ACKNOWLEDGEMENTS}

We would like to thank Nursali and Achmad Soleh as Annonaceae plant collections technician in PBG for their help on plant collections maintenance. Dewi Ayu Lestari contributed on designed the study, collected the data, checked editorial guidelines, wrote, read and approved the manuscript, but Abban Putri Fiqa contributed on performed data analysis, wrote, read and approved the manuscript.

\section{REFERENCES}

Anderson DP, Nordheim EV, Moermond TC, Bi ZBG, Boesch C. 2005 Factors influencing tree phenology in Tai National Park, Cote d'Ivoire. BIOTROPICA 37 (4): 631-640. Doi 10.1111/j.17447429.2005.00080.x.

Bawa KS, Kang H, Grayum M. 2003. Relationships among time, frequency, and duration of flowering in tropical rain forest trees. Am J Bot 6: 877-887.

Brennan K. 1996. Flowering and Fruiting Phenology of Native Plants in The Alligator Rivers Region with Particular Reference to The Ranger Uranium Mine Lease Area. Tourism House, Australia.

Brophy JJ, Goldsack RJ, Hook JM. 2004. The leaf essential oils of the Australian species of Pseuduvaria (Annonaceae). J Essent Oil Res 16: 362-366.

Cleland EE, Allen JM, Crimmins TM, Dunne JA, Pau S, Travers SE, et al 2012. Phenological tracking enables positive species responses to climate change. Ecology 93 (8): 1765-1771.

Dai DN, Hoi TM, Thang TD, Ogunwande IA. 2012. The leaf essential oils of five Vietnamese Desmos species (Annonaceae). Nat Prod Commun 7 (2): 231-234.

Danarto SA. 2013. Phenological leaves senescence of Fabaceae during dry season in PBG (case study of Fabaceae adaptation to water-limited) In: Aruminingtyas EL, Yanuwiadi B, Sumitro SB, et al. (eds) Proceeding of 4th International Conference on Global Resource Conservation \& 10th Indonesian Society for Plant Taxonomy Congress. Brawijaya University, Malang

Duarte MCT, Duarte RMT, Rodrigues RAF, Rodrigues MVN. 2018 Essential Oils and Their Characteristics. John Wiley \& Sons Ltd., USA.

Fournier G, Hadjiakhoondi M, Leboeuf M, Cave A, Charles B. 1997 Essential oils of Annonaceae. Part VII. Essential oils of Monanthotaxis diclina (Sprague) Verdcourt and Unonopsis guatterioides R.E. Fries. Flavour Fragr J 12: 95-98.

Fournier G, Leboeuf M, Cave A. 2011. Annonaceae Essential Oils: A Review. J Essent Oil Res 11 (2): 131-142. https://doi.org/10.1080/10412905.1999.9701092.

Handayani T. 2016. Flowering and fruiting time of Annonaceae species in Bogor Botanic Garden. Buletin Kebun Raya 19 (2): 91-104. [Indonesian]
Hatta H, Darnaedi D. 2005. Phenology and Growth Habits of Tropical Trees: Long-term Observations in The Bogor and Cibodas Botanic Gardens, Indonesia. National Science Museum Tokyo, Japan.

Janzen DH. 1974. Tropical blackwater rivers, animals and mast fruiting by Dipterocarpaceae. Biotropica 6: 69-103.

Karioti A, Hadjipavlou-Litina D, Mensah MLK, Fleischer TC, Skaltsa H. 2004. Composition and antioxidant activity of the essential oils of Xylopia aethiopica (Dun) A. Rich. (Annonaceae) leaves, stem bark, root bark, and fresh and dried fruits, growing in Ghana. J Agric Food Chem 52 (26): 8094-8098.

Khanduri VP, Sharma CM, Kumar KS, Ghildiyal SK. 2013. Annual variation in flowering phenology, pollination, mating system, and pollen yield in two natural populations of Schima wallichii (DC.) Korth. Sci World J 1-11. http://dx.doi.org/10.1155/2013/350157.

Kurten EL, Bunyavejchewin S, Davies SJ. 2018. Phenology of a dipterocarp forest with seasonal drought: insights into the origin of general flowering. J Ecol 106: 126-136.

Lestari DA. 2019. Evaluation of flowering and fruiting periods of selected Annonaceae species in Purwodadi Botanic Garden. AIP Conference Proceedings. 2120: 030023. https://doi.org/10.1063/1.5115627.

Mangun. 2006. Nilam. PT Penebar Swadaya, Jakarta. [Indonesian]

Micheloud NG, Castro DC, Buyatti MA, Gabriel PM, Gariglio NF. 2018. Factors influencing phenology of different Citrus varieties under the temperate climate conditions of Santa Fe, Argentina. Rev Bras Frutic 40 (1). http://dx.doi.org/10.1590/0100-29452018315.

Nanda A, Krishnamurthy YL, Suresh HS. 2014. Phenology of a tropical dry deciduous forest of Bhadra wildlife sanctuary, southern India. Ecol Process 3 (1): 1-12.

Nanda A, Suresh HS, Krishnamurthy YL. 2017. Phenology of tree species in a tropical evergreen forest of Southern India. Glob Ecol Conserv 6 (1): 1-12.

Panchen Z. 2016. Impact of climate change on flowering and fruiting times of Nunavut Arctic Plants. InfoNorth 69 (4): 444-449.

Phan GM, Phan ST, Konig WA. 2011. Chemical composition of the flower essential of Artabotrys hexapetalus (L.f.) Bhandari of Vietnam. J Essent Oil Res 19 (6): 523-524. https://doi.org/10.1080/10412905.2007.9699321.

Powo.science.kew.org. 2019. Artabotrys suaveolens, Cananga odorata and Desmos chinensis.

Putri DKY, Dewi IEP, Kusuma HS, Mahfud M. 2019. Extraction of essential oil from fresh cananga flowers (Cananga odorata) using solvent-free microwave method. J Chem Technol Met 54 (4): 793802.

Rusli MS. 2010. Success in Producing Essential Oils. PT Agro Media Pustaka, Jakarta. [Indonesian]

Syamsuwida D, Aminah A, Nurochman N, Sumarni EB, Ginting J. 2014. Flowering and fruiting development cycle and fruit set of Kemenyan (Styrax benzoin) at Aek Nauli. Jurnal Penelitian Hutan Tanaman 11 (2): 89-98. [Indonesian]

Tabla VP, Vargas CF. 2004. Phenology and phenotypic natural selection on the flowering time of a deceit-pollinated tropical orchid, Myrmecophila christinae. Ann Bot 94 (2): 243-250.

Thang TD, Dai DN, Hoi TM, Ogunwande IA. 2013. Chemical compositions of the leaf essential oils of some Annonaceae from Vietnam. J Essent Oil Res 25 (2): 85-91. http://dx.doi.org/10.1080/10412905.2012.755475.

Wahyuni R, Handoko C, Agustarini R. 2012. Preliminary study on the flowering and fruiting behaviours of Nyamplung (Calophyllum inophyllum Linn.). J For Res 9 (1): 1-10.

Winarni NL, Kurniasari DR, Hartiningtias D, Nusalawo M, Sakuntaladewi N. 2016. Phenology, climate, and adaptation: How does dipterocarps respond to climate? IJFR 3 (2): 129-141. 